\title{
Ixabepilone Regimen
}

National Cancer Institute

\section{Source}

National Cancer Institute. Ixabepilone Regimen. NCI Thesaurus. Code C160071.

A chemotherapy regimen consisting of ixabepilone that may be used in the treatment of advanced breast cancer. 